\title{
'Not like rose-tinted glasses... like taking a pair of dirty glasses off': A pilot intervention using positive emotions in expressive writing
}

\author{
Megan C. Hayes · Kate Hefferon
}

\begin{abstract}
Studies conducted in various contexts and with varied populations have found expressive writing enhances physical and psychological wellbeing. This pilot intervention study countered the predominantly quantitative evidence by adopting a qualitative methodology, exploring the experience of using positive emotions in expressive writing. Participants $(n=10)$, who all had previous experience in expressive writing, were asked to select one of ten positive emotion cards (PECs) each day for three days. Participants were then asked to write expressively through the 'lens' of their chosen emotion. Semi-structured interviews were conducted and experiences were evaluated using Thematic Analysis. The results identified two main themes that compared the experience of expressive writing both with and without the PECs. The first theme, Processing (without the PECs) contained three sub-themes: sense of relief, habitual perspective and reactive to experience. The second main theme, Progressing (with the PECs) contained three different sub-themes: sense of direction, changed perspective and interactive with experience. This study found that, for expressive writers, positive emotions may function in three ways: to relate to others or self-expand, to move past challenges cognitively or change unconstructive perspectives, and finally as a way to interactively link or 'bridge' from the written subject matter to constructive action, thus breaking cycles of reactive writing and rumination. Implications of the study on the practice of expressive writing and its potential as a positive psychology intervention (PPI) are discussed.
\end{abstract}

Keywords: expressive writing, positive emotions, emotional processing, thematic analysis, positive psychology

\section{Introduction}

Since the 1980s the field of expressive writing (Pennebaker \& Beall, 1986; Pennebaker \& Chung, 2011), which demonstrates the various emotional and physical health benefits of writing about one's 'deepest thoughts and feelings', has been extensively studied via quantitative methods (for a review see Frattaroli, 2006; Sloan \& Marx, 2004). Six years ago, the Journal of Health Psychology ran a special issue which stressed the need to move 'beyond expressive writing' (Nicholls, 2009) by exploring qualitative approaches to the paradigm. Yet, to date, qualitative research literature remains virtually non-existent in the field, with quantitative research enduring as the favoured - or at least more widely published - approach (Hoyt, Austenfeld \& Stanton, 2014; Teismann, Het, Grillenberger, Willutzki, \& Wolf, 2014). This is salient in that leading researchers have themselves admitted "no single theory appears to account for the effectiveness of the writing paradigm" (Pennebaker, 2004, p.138), despite its observable array of emotional and physical 
health outcomes (Baikie \& Wilhelm, 2005) including social effects (Lepore \& Greenberg, 2002; Slatcher \& Pennebaker, 2006), mood (Teismann et al., 2014) and coping (Hoyt, et al., 2014; Spera, Buhrfeind \& Pennebaker, 1994). Though Pennebaker and colleagues have observed that the writing paradigm is not a cure-all, nor benefits everyone (Niederhoffer \& Pennebaker, 2009), we posit that a qualitative approach may assist in building a richer theoretical model of when, why and how it does work - thus furthering this proposed movement 'beyond expressive writing'.

\subsection{Positive psychology and expressive writing}

The field of positive psychology, considered the scientific study of wellbeing and human strengths (Carr, 2011; Seligman \& Csikszentmihalyi, 2000), has embraced Pennebaker's expressive writing paradigm with enthusiasm. It is cited as a useful intervention in The Oxford Handbook of Positive Psychology (Lopez \& Snyder, 2009) and other general reference works in the field (Parks \& Schueller, 2014; Snyder, Lopez \& Pedrotti, 2010). This enthusiasm, however, has tended to overlook what Pennebaker and colleagues themselves recognise as the paradigm's entirely negative focus, writing about trauma, and so in essence dwelling on our miseries. They point out the irony, then, that expressive writing has become a feature of positive psychology (Niederhoffer \& Pennebaker, 2009). That said, adaptations of the original expressive writing paradigm abound, from the inclusion of narrative instruction (Danoff-Burg, Seawell, \& Agee, 2010) to adding a mindfulness component (Poon \& Danoff-Burg, 2011). Amongst such adaptations, several are specifically positive, yet each has its own limitations given developments in the field of positive psychology. Such developments include contentions about accentuating positivity (Held, 2002), causing a gradual shift toward a more nuanced 'Positive Psychology 2.0' (Wong, 2011) or a 'Second Wave', dialectic conception of positive psychology (Ivtzan, Lomas, Hefferon \& Worth, 2015). For example, benefit-finding (King \& Miner, 2000) offers a way for writers to positively re-frame traumatic events. However, we posit that similar re-framing might be achieved without necessarily perceiving an explicit benefit. As an example, when grieving the death of a loved one, writing with emotions of hope or serenity could feel more appropriate and comforting than actively searching for positive benefits from the traumatic experience. Equally, other examples of positively-focussed writing interventions such as writing about our 'Best Possible Self' (King, 2001) or 'Intensely Positive Experiences' (IPEs) (Burton \& King, 2004, 2009) whilst found to be beneficial, for example in increasing emotional intelligence and lifesatisfaction (Wing, Schutte \& Byrne, 2006), also lack the nuance sought by Second Wave positive psychology. Such interventions, it could be argued, have a one-dimensional conception of what it is to be positive, and provide little scope for constructively processing challenging feelings and experiences. Thus, two objectives of the present study were 1) not to limit the subject matter of the writing to positive events, but rather to simply offer the 'lens' of a positive emotion, and 2) to offer a wide spectrum of emotions to select from, including emotions such as awe, interest and serenity, to promote a range of emotional responses to the events of one's life that were not just typically 'happy' emotions. The researchers hoped that this adaptation would preserve the efficacy of the original writing paradigm (Pennebaker, 1997; Pennebaker \& Beall, 1986) whilst consolidating it with research into positive emotions and the many benefits of experiencing these emotions, which we will now outline. Then might we truly adopt the writing paradigm as a cornerstone intervention of positive psychology (Parks \& Schueller, 2014) in a manner appropriate to the 'second wave' developments of the field (Ivtzan, Lomas, Hefferon \& Worth, 2015). 


\subsection{Positive emotion in expressive writing}

Emotions have been central to the writing paradigm since the original study, which demonstrated that writing the facts of a trauma alone does not result in significant improvements in physiological, health or self-report measures and that emotional expression is integral to the efficacy of the intervention (Pennebaker \& Beall, 1986). Currently, numerous theories seek to explain the underlying mechanisms of the expressive writing paradigm and its efficacy. The most prominent of these are emotional inhibition and cognitive processing (Niederhoffer \& Pennebaker, 2009), although conflicting theory cites self-affirmation as a more prominent mediator in the effectiveness of writing (Creswell et al., 2007). Whilst this debate continues in the literature, we posit that one largely under-researched avenue to further substantiate the theory of expressive writing is a qualitative analysis of the function of positive emotions.

In the field of positive psychology much research has been completed on the experience and function of positive emotions, in no small part pioneered by the work of Alice Isen (Ashby \& Isen, 1999; Isen, Daubman, \& Nowicki, 1987) and Barbara Fredrickson (1998, 2001). Fredrickson's 'Broaden-and-Build' theory has been well documented and argues that significant positive emotions ${ }^{1}$, namely: love, joy, interest, awe, inspiration, gratitude, hope, serenity, amusement and pride (Fredrickson, 2009), "broaden people's momentary thought-action repertoires and lead to actions that build enduring personal resources" (Fredrickson \& Cohn, 2010, p.782). Researchers have already begun to explore the links between this theory and expressive writing (Burton \& King, 2009) yet to date no known study has explored these links from a qualitative perspective. The purpose of this present study, then, was to qualitatively investigate whether 'Broaden-andBuild' theory and/or other similar psychological processes were experienced when positive emotions were incorporated into expressive writing.

Recent studies have pitched "positive writing" - whereby participants are asked to write "the most intensely positive experience" of their life "or an extremely important positive issue" that has affected them - against "expressive writing-as-usual" in participants with mood disorders and found that health outcomes were the same (Baikie, Geerligs \& Wilhelm, 2012) in keeping with previous research, illustrating that writing may have an effect whether or not it focuses on traumatic experiences (Burton \& King, 2004; King, 2001). Building on these findings, in the present study we assert that the addition of specific positive emotions into the writing intervention, yet without limiting the subject matter of the writing, may have a host of benefits over and above those associated with "expressive writing-as-usual." Why might this be deemed an important addition to the practice of expressive writing? Research since the 1970s has shown that social benefits accrue from the experience of positive emotions. For example, Isen and Levin (1972) and Isen (1987) demonstrated that when we feel increased positive emotions, we tend to act with increased kindness and engage in more pro-social behaviours. Beyond this, researchers have shown that regular experiences of positive emotions can contribute to physical and mental wellbeing, connect us to others and potentially promote resilience in times of hardship (Fredrickson, 1998, 2001). Again, it is important to note that, in line with 'Second Wave' positive psychology (Ivtzan, Lomas, Hefferon \& Worth, 2015) and the emergence of compelling evidence regarding the "light" and "dark" side of positive emotions (Gruber \& Moskowitz, 2014), there is a strong argument for a synthesis of the "positive" and "negative" in an expressive writing paradigm. In other words, by developing this pilot intervention, we recognised the value of

\footnotetext{
${ }^{1}$ Again, the authors recognise that what is termed a "positive" emotion does not always imply something "good" and that what is termed a "negative" emotion does not always imply something "bad". Further, the experience of both "positive" and "negative" emotions, depending on duration and context, could lead to both adaptive and maladaptive outcomes (for more on this debate, please see Gruber \& Moscowitz, 2014; Ivtzan et al., 2015).
} 
engaging with the negative (writing about trauma) whilst simultaneously highlighting the benefits of positive emotions, and the many shades and complexities of these emotions. Thus, although this study focuses on the inclusion of positive emotions within expressive writing, we do not suggest that so called "positive emotions" are more important than other emotions or that these emotions should be attained at the cost of feeling other "types" of emotions.

Finally, expressive writing researchers have asked whether the language used in the writing paradigm is reflective of personal changes, and more importantly how prescriptive a given writing exercise can be (Niederhoffer \& Pennebaker, 2009). Researchers have made extensive use of computerised language analysis of writing samples to address this question (Tausczick \& Pennebaker, 2010). By such methods, positive emotion words such as 'happiness', 'enthusiasm' or 'amusement' in participants' writing have been shown to mediate the efficacy of expressive writing (Pennebaker \& Chung, 2007; Pennebaker \& Seagal, 1999). We posited that this offered a clear rationale for developing an adaptation of the original paradigm that might encourage greater positive emotional expression. However, from a qualitative perspective, computerised language analysis alone would not be considered a rich or nuanced enough approach to capture how positive emotion in writing is experienced at the time of (and following) a writing exercise. To accomplish that, we have chosen a Thematic Analysis. This present study, then, explored one possible method for encouraging a greater use of positive language - with the aim of improving the efficacy of the paradigm - whilst avoiding limiting the writer by prescribing that they write only about positive events, or specific 'benefits' of an event.

Nicholls (2009, p. 177) cites the lack of "first-person accounts of what the experience of writing feels like", which would enable "new research that will help us to find ways of specifying and further exploring our experiences of writing", as a gap in the expressive writing literature. The current study was therefore devised to gather such first-person accounts, and uses Thematic Analysis to specify not just when or how often, but in what ways positive emotions are felt and experienced in expressive writing, to answer the research question: How do positive emotions function in a 'positive journaling' intervention?

\section{Methodology}

\subsection{Research design}

This qualitative study was designed to keep participant experiences at the core of the analysis by taking an inductive approach in exploring first-hand accounts of how positive emotions function in expressive writing. The research question was: How do positive emotions function in a 'positive journaling' intervention. Data collection was completed via semi-structured interviews with participants $(n=10)$ following a writing intervention over three consecutive days, in line with Pennebaker (1997). The transcribed interviews formed the data corpus and were analysed. Thematic Analysis (Braun \& Clarke, 2006) was used because it is considered "still the most useful in capturing the complexities of meaning within a textual data set" (Guest, MacQueen \& Namey, 2012, p.11). This approach entailed coding each transcript for prevalent themes, before synthesizing these into a thematic map. The ultimate purpose of this Thematic Analysis was to generate a broad overview of the commonalities in each individual's experience. All transcripts and forms remained confidential and participants' names were changed to preserve anonymity. In epistemological terms, the researchers employed a phenomenological and constructionist approach, and as such were sensitive that all the data were co-constructed between researcher and participants. Throughout the study the primary researcher remained aware of her role as a white, western, female and was conscious of how this might shape her interpretation of 
participant accounts. As far as possible, scrutiny was paid to the researcher's personal biases and any preconceptions to avoid detrimental influence on the analysis.

\subsection{Compliance with ethical standards}

Ethical approval for the study was obtained from the Research Ethics Committee of the University of East London. The authors declare that they have no conflict of interest (financial or non-financial) and that no funding or sponsorship for the study was provided. Informed consent was obtained via distribution of consent forms to all participants, which were then completed and returned by email so as to avoid participation in the study being limited by location.

\subsection{Participants and recruitment}

A convenience sample of participants $(n=10)$ was recruited, both female $(n=8)$ and male $(n=2)$. Participants were not screened for the study by gender, ethnic origin or age although, in line with informed consent, all participants were over 18 years of age and under 65. Recruitment was conducted primarily via the Facebook page of Lapidus ${ }^{2}$, a therapeutic writing organisation; thus the majority of participants were experienced in writing expressive journals and most kept a regular practice of this. Participants were self-selected for the study. Participants completed the intervention independently, at home and in their own time rather than in a lab, and in most cases completed the 30-minute, semi-structured interviews within two weeks of the three-day expressive writing intervention. No incentive was offered for participation.

\subsection{Materials}

A set of ten physical 'positive emotion cards' (PECs) were distributed to participants by post. The emotions included were love, joy, interest, awe, inspiration, gratitude, hope, serenity, amusement and pride, which have been demonstrated to be the positive emotions we tend to experience most often and which have been reviewed by researchers (Fredrickson, 2009; 2011; please see Condon, Wilson-Mendenhall \& Feldman-Barrett, 2014 for expansion on "types" of positive emotions). Cards were two-sided, with the name of the emotion on one side, and instructions on the reverse, as shown in Figure 1 below.

The instructions on the cards contained elements of the basic expressive writing paradigm (Pennebaker, 1997) and guidance from the 'positivity portfolio' exercise proposed by Fredrickson (2009) with the aim of encouraging as much engagement with the chosen emotion as possible. Participants then used the PECs alongside their normal method of journaling, which tended to be either a specific notebook or loose sheets of paper. Interviews were conducted via Skype and were recorded with an iPad using the QuickVoice application.

Figure 1: Example of Positive Emotion Cards (PECs)

\footnotetext{
${ }^{2}$ Further information regarding the work of Lapidus can be found at www.lapidus.org.uk
} 
How to use this emotion card:

1. Choose just ONE emotion card each day.

2. Think about how the emotion FEELS to you.

3. REFLECT on the emotion as you write in your journal.

4. Be DETAILED; describe the emotion.

5. You may write about your PAST, PRESENT and FUTURE.

6. Choose to see any negative events or thoughts through the LENS of your chosen emotion.

Pride. Joy. Amusement. Serenity. Gratitude. Hope. Awe. Inspiration. Interest. Love.

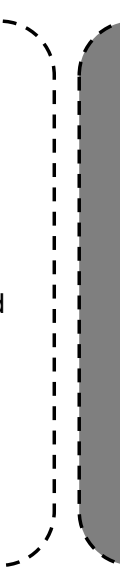

\subsection{The writing intervention}

Expressive writing researchers have stated, "the more that the topic or writing assignment is constrained, the less successful it usually is" (Pennebaker \& Chung, 2007, p.267). For this reason, participants were instructed simply to write about their day for between 15 and 30 minutes using the chosen PEC, relating this to their past, present or future should they choose. Instructions were closely based on the standard expressive writing paradigm (Pennebaker, 1997) and were as follows:

For the next 3 days, write for 15 to 30 minutes each evening reflecting on your day. You may like to tie this in with your relationships with others, including parents, partners, children, friends or other relatives; to your past, your present or your future; or to who you have been, who you would like to be or who you are now.

Each day, choose one of the ten 'Positive Emotion Cards' (PECs). Which PEC feels most relevant to your day, or would you most like to apply to your day? Sit with all the cards quietly until you have chosen one, and then begin writing.

\subsection{Interviews}

Once this intervention had been completed, thirty-minute semi-structured interviews were carried out with each participant individually, focussing on their experience of writing in the past versus writing with the PECs. Questions centred on why participants chose specific emotions and how they felt both prior to and following the writing.

Participant's writings were not collected. We felt that this enabled participants to be more candid in their writing, and thus to provide richer accounts of how they experienced positive emotions in the writing, which was the focus of the study. Some participants, however, did choose to read small pieces of their writing aloud at interview stage. Following the interviews, participants were provided with debrief sheets, which outlined how their data would be used and included researcher contact details.

\subsection{Analysis}

The full data corpus consisting of the verbatim transcripts of the 10 participant interviews was coded by the researchers and then examined using Thematic Analysis in accordance with the method set out by Braun and Clarke (2006). The primary researcher transcribed the interviews so as to ensure greater familiarisation with the data. Each transcript was coded first for initial codes, and then a second time to draw out recurrent codes across the whole data set. Recurrent 
codes became themes that were felt to capture significant patterns of response across the group in relation to the research question: How do positive emotions function in a 'positive journaling' intervention? These themes were gathered into an initial thematic map, as well as several developed versions before a final thematic model was completed, composed of two main themes and six sub-themes

\section{Results and Discussion}

Though it was not an explicit criterion for participation, the majority of participants kept a regular journal and all had experience of journaling. Therefore the Thematic Analysis resulted in a comparison between this typical expressive journal writing and the present pilot intervention. Whilst this previous expressive journal writing might not be considered 'standard' expressive writing (given the writers followed no scientific instruction) the researchers felt this journal writing could justifiably be referred to as expressive because the inherent nature of the act writing about one's 'deepest thoughts and feelings' - was the same. The analytical process resulted in a thematic map of these two parallel main themes, as well as six sub-themes, as shown in Figure 2 below.

Figure 2: Thematic Analysis of Positive Emotion Cards (PECs)

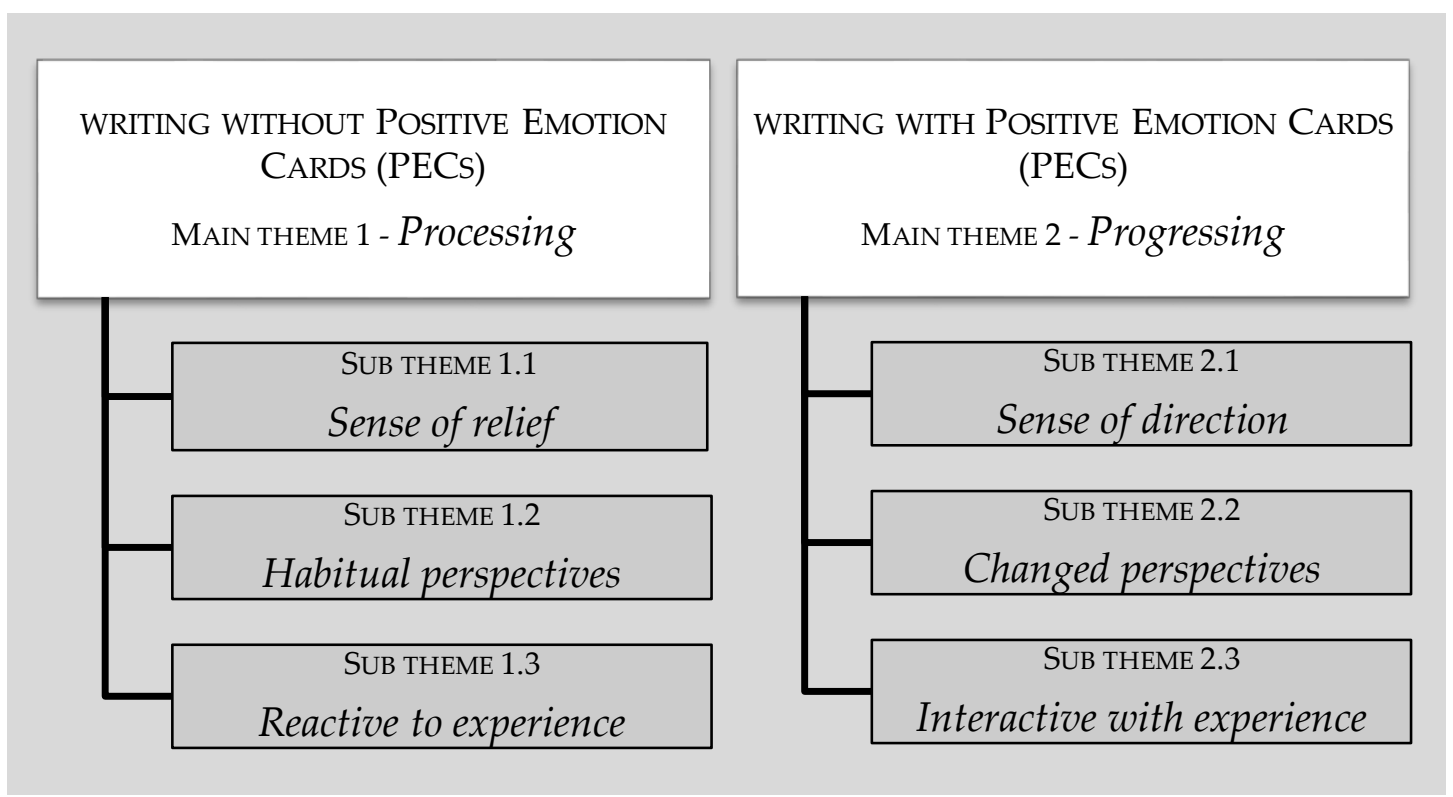

The two main themes were 'processing', for expressive journal writing (without the PECs) and 'progressing', for expressive writing (with the PECs). This can be likened to recent studies demonstrating the nature of unconstructive processing (e.g. rumination) and constructive processing (e.g. problem-solving) in expressive writing (Hoyt, et al., 2014; Stanton, 2011). Participants stated unequivocally in their accounts that their previous writing had, largely, made them feel better, as the wealth of expressive writing literature attests to; yet specific focus on positive emotions in the pilot intervention appeared to do something more, with participants stating that they felt they had made progress in the writing, typically by having reached a point of changed perspective that was more constructive. Therefore, our original research question concerning the function of positive emotions in expressive writing is addressed by the second main theme of 'progressing.' Three sub-themes combined to support 'progressing' as the main theme of expressive writing with the PECs, all of which referred to movement, change or a 
cognitive progression from the page back to real world circumstances or future actions. This contrasted with 'processing' as the theme of expressive journal writing. Here the subthemes illustrated that, though there was some development through a sense of relief in the writing, there was a clear lack of progress beyond this, with participants instead describing "habitually" looking "at the bad stuff" (Amanda) and reacting to life experience without a self-efficacious element; the writing was a way to feel better, but not to flourish. Prevalence of these two parallel main themes and six subthemes is shown in Table 1 and will now be discussed in more detail.

Table 1: Prevalence of themes in participant accounts

\begin{tabular}{lcc}
\hline Main Themes and Subthemes & Participants $(\boldsymbol{n = 1 0 )}$ & (\%) \\
\hline 1. Expressive Writing (without PECs) as 'Processing' & & \\
1.1 Sense of Relief & 7 & $70 \%$ \\
1.2 Habitual Perspective & 7 & $70 \%$ \\
1.3 Reactive to Experience & 7 & $70 \%$ \\
2. Expressive Writing (with PECs) as 'Progressing' & 7 & \\
2.1 Sense of Direction & 8 & $80 \%$ \\
2.2 Changed Perspective & 8 & $80 \%$ \\
2.3 Interactive with Experience & & \\
\hline
\end{tabular}

Themes are presented in an order that we felt captured the cognitive journey of the participants in sequential order. Firstly, their previous journaling experience as 'processing' (Main Theme 1) was interpreted as a sequence of feeling relief (Subtheme 1.1) yet often ruminating (ST 1.2) in a manner that was usually reactive to experience (ST 1.3). Secondly, using the PECs as 'progressing' (MT 2) was interpreted as a sequence of feeling directed (ST 2.1) toward a changed perspective (ST 2.2) in a manner that was usually interactive with experience (ST 2.3). Selected quotes are provided that the researchers felt typified the themes.

\subsection{Main Theme 1: Expressive Journal Writing (without PECs) as 'Processing'}

This main theme integrates three subthemes, each detailing how the participant's previous journal writing was very much a method of "dealing with" (Rose) challenging circumstances and emotions, though not necessarily moving beyond them, as in unconstructive processing (Hoyt, et al., 2014). As Laura comments in regard to her previous journal writing:

"Looking back, which I do sometimes to those early journals, I can see how I tried to motivate myself a lot through writing, but at the same time it was a place to download or offload a lot of negative feelings, a lot of difficulties, which were just repetitive." (Laura)

This theme coincides with previous findings in the research literature citing cognitive processing as one of several key theories underlying the efficacy of the writing paradigm; writing provides participants with a better understanding of themselves and challenging personal circumstances (Niederhoffer \& Pennebaker, 2009). Yet here Rose describes her previous expressive journal writing as a way of processing, but again not necessarily moving on from challenging circumstances:

(Researcher) "Okay, can you tell me a little bit about how you would use a journal, what kind of purpose it would fulfil?"

(Rose) "Um, it was really, kind of, just a way of, I suppose, getting stuff in my headthoughts in my head - out and onto paper, kind of just trying to kind of process things that I found difficult or that were making me emotional..." 
(Researcher) "And what does 'process' mean to you?"

(Rose) "Um, I suppose just kind of, um, get it out of my head and, you know, see if I can kind of work out why I'm finding things difficult and then perhaps move on from them, so it's a kind of a way of... yeah I suppose dealing with things that are, kind of, psychologically difficult. But kind of taking them out of your head and into a kind of more physical form."

Rose notes here that she could "perhaps" overcome personal challenges, but later in her interview stressed that she often simply "wallowed in the difficult stuff" without any sense of progress. Her description of writing as a way to process became the title of this main theme. The three subthemes that combined to form this first main theme of 'processing,' sense of relief, habitual perspective and reactive to experience, will now be discussed individually.

\subsubsection{Subtheme 1.1: Sense of Relief "like scratching an itch"}

The subtheme sense of relief was drawn from the multiple ways in which participants described their typical expressive journal writing as a kind of "download" (Laura) of their thoughts onto paper, and the subsequent feeling of liberation. Participants described their typical writing as "an aid of getting words out of my head, onto paper" (Louise), "a container" (Laura), "a repository" (Rita) and even a place to "vomit" (Amanda) negative emotion, which appears to concur with existing theory on inhibition and disclosure (Niederhoffer \& Pennebaker, 2009). Writing as a relieving practice was clearly seen as beneficial by participants, and in some cases even essential to normal functioning:

"I'll have things going round and round and round in my head and I'll have an urge to just write... I can't concentrate... I just have to get my journal out and write and it kind of gets the stuff out of the way, and then I might be able to do something else instead." (Amanda)

The page was a place to unload, or process challenges; yet it was not a place to build optimism, a sense of self-efficacy or to feel one had made progress. Writing was typically a way of returning to normal, not necessarily of thriving. This is not to devalue it; it was clearly of paramount importance as a coping mechanism to these participants. However, as Nicholls (2009, p.174) observes, this manner of "letting go" may be merely a starting point or first phase to the potential of a writing practice to impact wellbeing, which this new study hopes to demonstrate.

\subsubsection{Subtheme 1.2: Habitual Perspective or the "negative comfort zone"}

The subtheme of habitual perspective was drawn from participants' accounts of their typical expressive journal writing as tending to be negative and repetitive:

"I would write about all the stuff that was going around in my head. Invariably it would be quite negative." (Jane)

This theme was expressed in seven of ten of the accounts transcribed. These habitual perspectives were primarily negative, with participants repeatedly stating that they were not driven to write when they felt positive:

"I think when you're in a positive mood, I don't always, um, journal because I'm either, you know, I'm enjoying what I'm doing or um... so, uh, yeah, maybe I don't journal as much when I'm positive." (Louise)

or simply that they did not notice when they felt positive, with lower emotional recognition relating to positive emotion: 
"I notice when I feel stressful or anxious... I don't really have this awareness when it comes to positive emotions, now that I think of it, I never stop and notice" (Mark)

"...you are not always conscious about the things you think and how you're thinking them, you know?" (John)

As such, this impetus to write about negative thoughts and feelings often led participants to ruminate or stay stuck in cycles of thought which they had difficulty moving past. Here Laura describes her writing as an "obsession" with a challenging topic:

"...the rest of the diary beforehand is all my obsession with weight loss [laughs]. So... so

it's very much a potpourri my journal writing and it will be whatever I'm feeling or thinking about or focussing or obsessing about." (Laura)

Although expressive writing research has demonstrated some efficacy in lowering rumination (Gortner, Rude, \& Pennebaker, 2006) these results have been modest and moderated by constructive or unconstructive styles (Hoyt, et al., 2014). The present study indicates that regular practice of expressive journal writing may typically lead participants to unconstructively process, or ruminate, and that the addition of the PECs decreased this tendency, as will be demonstrated in the next main theme.

\subsubsection{Subtheme 1.3: Reactive to Experience "if I've had a tiresome day"}

This subtheme attempts to capture the manner by which participants described their journaling as an activity they would turn to in response to a bad day or difficult circumstances, which almost all participants were dealing with in varying degrees, from a loved one facing terminal illness to divorce. This was often described as a simple input-output process, with the challenge being relieved onto the page as we have seen demonstrated in the theme sense of relief, but without necessarily relating back out from the page to real experience; simply coping with it. Here one participant describes her process:

"I tended to be dredging things up... facing them... dealing with them" (Jane)

This also linked with the theme of habitual perspective in that, as participants tended to write when they felt negative, their writing - although helpful as a coping mechanism - was invariably negative:

"I have an impetus to write when I'm not feeling good" (Amanda)

"...verbalising - and that means writing as well-about problems or issues is incredibly helpful" (Becky)

It was often very specific circumstances that initiated the writing as a form of coping or processing:

"My marriage has kind of been ending, it's kind of been ending for a long time; it ended last year. Um... and I think... mostly that's caused me to want to write really." (Amanda)

"...if I've had a tiresome day or things have happened, um, I mean my dad is very poorly at the moment, so I've had times when I've written about that." (Louise)

This theme of reactive writing highlights expressive journal writing as a form of coping, which the literature supports, from coping with job loss (Spera, Buhrfeind \& Pennebaker, 1994) to a broken heart (Lepore \& Greenberg, 2002). 
Each of these subthemes supports the idea that expressive journaling typically acted as a method for processing negative emotion or circumstances. Yet although this often led to participants feeling better, it did not necessarily progress to their feeling good (i.e. strong and well) as is arguably one of the primary aims of positive psychological research: to "help people become lastingly happier" (Seligman, Parks \& Steen, 2004, p.1379). Participants rarely referred to feeling happy as a result of the writing, or efficacious or resilient; rather, they felt at best relieved and at worst stuck in ruminative cycles of negative writing. Despite the fact that this writing-as-usual was evidently a valid coping mechanism, it did not appear to contribute to enhanced wellbeing or to flourishing. As Amanda commented:

"When I'm kind of glum and I need to write something down, I don't think it makes me more glum."

Most of us would agree that the mere absence of glumness is not the same as experiencing flourishing or wellbeing.

We now move to a discussion of the second main theme that was drawn from the intervention writing: expressive writing (with PECs) as progressing. Here we focus on participants' accounts of writing with the PECs, and thus specifically address the research question of the function of positive emotions in expressive writing.

\subsection{Main Theme 2: Expressive Writing (with PECs) as 'Progressing'}

This second main theme summarises the way in which participants used positive emotions to progress beyond challenges, either by relating to others, reframing difficult circumstances or strategising for the future. This main theme had three subthemes: sense of direction, changed perspective and interactive with experience. A key factor in this adaptation of the writing paradigm was that it did not simply ask participants to write about positive things: participants were invited to write about whatever they felt they wanted to, yet as far as possible to relate this to their chosen PEC. However, this did not appear to result in escapist or, as Louise joked, "Pollyanna-ish" writing. As Rose commented:

"I wasn't, you know, sort of just thinking about flowers and hearts and nice clouds... it was more trying to sort of [pause] assess." (Rose)

This comment typifies that, despite being free to write about negative feelings if they wished to, participants tended toward a kind of positive realism that was optimistic without being idealistic, which we will now evidence in the subthemes.

\subsubsection{Subtheme 2.1: Sense of Direction "I wasn't just wandering about"}

The theme sense of direction captures the prevalence of participants who described writing with the PECs as a kind of directed journey:

"I've just re-read those three pages and they really are quite deeply and honestly reflective... the cards gave me a focus as I wasn't just wandering about... it feels a bit constrained to start with but then it was a good structure..." (Laura)

“...on all three days I did the same thing where I kind of went through this journey of thinking around a word and thinking about things in my life, and then there was always 
this kind of... you know, I always came to this kind of point where it made me reflect on things in a new... in a way that I perhaps hadn't before." (Rose)

"...it felt more like there was this... this sort of centripetal force drawing the writing in so

it wasn't, it wasn't sort of going off on one, it was, you know, it was all related" (Valerie)

There was a tendency to describe this in physical terms, as the examples above show. This was interpreted by the researchers as a way of forming narratives in the writing (Danoff-Burg, et al., 2010) centred on the chosen emotion; Mark, for example, described one of his chosen PECs as "a tool... to explore." The addition of the positive emotion in the writing helped participants feel "more connected" (John) or to "put a few connections together" (Rose) and this manner of joining the dots, as it were, led to a sense of having gone somewhere in the writing, or progressed. As Jane commented, "I felt in a better place for having done it", or as Rose said, "It led me down a path." The "path" or "place" was normally one of changed perspective, which is the next subtheme.

\subsubsection{Subtheme 2.2: Changed Perspective "Not rose-tinted glasses...like taking a dirty pair of glasses off"}

The theme of changed perspective captures how the participants came to form new perspectives on their life experiences when using the PECs, particularly those that were challenging. Early and current research (e.g. Fredrickson, 1998; Isen, 1987; Wadlinger \& Isaacowitz, 2006) has argued for the "broaden effect" of positive emotions and this was evident in this theme. Here, when participants focussed on a certain positive emotion, they seemed to display broadened mind-sets by considering alternatives, assessing a wider range of experiences, and in some cases even challenging long-held beliefs. For example, when Rose wrote with the Hope card she commented:

"...here's an experience in my life that I hadn't previously thought of as being particularly hopeful or particularly loving, but actually it was." (Rose)

Other participants, speaking more generally about using positive emotions in the writing, made similar comments.

"...it gave me this perspective on a few things that are part of my life but haven't really been part of my life at the same time - because I didn't notice them." (Mark)

"I don't consistently write in that [positive] way ... if it was a piece of music it would be a different key to play in." (Laura)

The broaden effect was particularly evident in the way participants spoke about challenges, which we have seen almost all the participants felt they were facing in varying degrees. Yet this change of perspective, whilst positive, again tended to be decidedly realistic. Jane, who also chose Hope, commented:

"I suppose the hope came from... um... [pause] looking at things differently, through like a filter if you like. Not rose-tinted glasses, because that implies a lack of reality, but it is, I think, a bit like taking a dirty pair of glasses off" (Jane)

Several participants also commented that this was the first time in memory that they had considered their experiences in relation to specific positive emotions, and so they reflected on the novelty of this: 
"I was able to write in a way - I was able to write about things - in a way I wouldn't usually write about because I don't necessarily look at my life from a perspective of hope." (Mark)

Again in line with Fredrickson's work $(1998,2001)$ and the "Broaden-and-Build theory," we might be justified in assuming that this broadening of mind-set on the page may result in the building of personal resources for the future, which the next and final subtheme seemed to support.

\subsubsection{Subtheme 2.3: Interactive with Experience "I felt more capable"}

We have discussed how the present analysis pertains to existing research on the Broaden-andBuild theory of positive emotions (Fredrickson, 1998, 2001). However, what was most interesting in the data corpus was the emergence of a novel theme which presents a third potential dimension to the function of positive emotions in the practice of expressive writing: what we have termed the 'bridge' effect. Rather than using the page as a mere 'dump' of their emotions as they typically did when writing (this was described as a very one-way trajectory of the input of life experience and the output of this onto the page, resulting in relief), participants went on to engage in a further step. In this step they were able to relate what was on the page back out to real experience and strategise future actions; to bridge back from the private inner world explored on the page to an outer world, with a sense of their self-efficacy to meet challenges. In their previous journal writing - which seemed to be primarily a repository for negative emotion - often (though not always) participants would ruminate and get stuck in unconstructive loops; "patterns of thought" as Rose called it, or the "negative comfort zone" as Amanda commented. In contrast, positive emotions seemed to provide a bridge between the writing and real life. This was interpreted in the data analysis as a manner by which participants cognitively progressed past challenging life circumstances rather than simply processed or felt relief from them, which lead to feelings of both positive affect and self-efficacy:

"I looked at, um, the event I wrote about in a different way than I probably would have done some years ago... And, uh, well, I felt more capable of doing things... well with more... more good things to offer." (John)

"I wrote a list of things that I would be proud of in the future." (Laura)

"I kind of came out of it feeling more positive, like I'd kind of made some progress." (Rose)

Even in one case where a participant, Amanda, "found it really difficult" to relate to the PECs and, in her own words, "resisted it quite a lot," stating that the emotions "felt kind of irrelevant," when she read back on her journal writing during the interview, she noted that, retrospectively, she could see the benefit of the intervention:

"Um... well now looking back I think it's probably a good thing to do...It's sort of making me think of good things in my life." (Amanda)

The bridging effect from the page to real action was often expressed in relation to others. In cases when the use of the positive emotions was most embraced by the participants - particularly love - this assisted in linking the self with others (Fredrickson, 2013). This broadening of the sphere of self has already been demonstrated as a function of positive emotions by (e.g. Fredrickson, Cohn, Coffey, Pek, \& Finkel, 2008; Johnson \& Fredrickson, 2005) and this phenomenon can be rationalised as self-expansion, as per the findings of Aron, Aron, \& Smollan (1992). This was most poignantly evidenced in the present study through this account by Jane: 
"I think when I wrote with Love... my experience was that I didn't have any hard edges. So whereas I might have thought... my husband coming in and saying 'oh, is there anything I can do to help with [dinner]?' when I've already done everything, if I wasn't writing about that with love, I could quite easily have gone into a judgmental place and thought... do you know, you always do that. You come in and you ask (laughs) if I want any help when I've finished, or almost finished. And, where I come from if I'm using a love filter is, nah it's okay I've done it - but you could make me a cup of tea." (Jane)

Here Jane does not simply react to a difficult situation with her husband by 'dumping' it onto the page; instead she first reframes it and then modifies future actions in line with this reframing. The positive emotion of love acts not only as a bridge connecting Jane and her partner, but a bridge between Jane's private writings and her real experiences. When she wrote with positive emotions, she describes acting in accordance with what she has written, changing her actions to more pro-social behaviour and increasing her sense of self-efficacy to handle a potentially aggravating interaction with her husband. Through the writing she both self-expands and strategises for the future; she builds a bridge between her sphere of self on the page and the wider sphere of her inter-relational experiences. This novel finding is in line with research on the social effects of the writing paradigm (Slatcher \& Pennebaker, 2006).

Importantly, the more participants engaged with the positive emotions, particularly love, the more they described focussing on others in their writing. Love was by far the most chosen of the PECs, picked by seven of the ten participants and the only card to be picked twice by any participant. One participant did discuss "self-love" (John), or self-esteem, but participants primarily expressed their love for others. Conversely, those who resisted engaging with the PECs tended to speak more about the self as an individual, with little reflection on their relationships. For example, in Becky's case, she did not choose love and noted that she "felt really resistant" to the PECs. She then described writing about her mood and her childhood, with virtually no mention of others. Further, Becky referred to writing as a way to "transcend" or leave behind the everyday - such as arguments with a partner - rather than a space to work out ways of improving these difficult life circumstances. Thus, actively engaging with the positive emotions, particularly love, seemed to be linked with a focus on others. When the PECs were embraced, participants actively reframed their interactions with others, even those interactions that were challenging, rather than just avoiding or 'transcending' them in the writing, as we see in Jane's account above. Participants who embraced the PECs dwelled on support networks, reframed relationships, and were grateful for good qualities in others:

"I just sort of felt gratitude for people's calmness and, you know, sense of perspective and so on." (Valerie)

"If I think of love in a different way you know... they are experiences of love that I've had." (Rose)

This finding, that the PECs assisted participants in relating to others, was interpreted in line with previous research demonstrating that positive emotions can increase a sense of connection to others (Johnson \& Fredrickson, 2005). 


\section{Conclusion}

Positive emotions in expressive writing appeared to function very much in accordance with Fredrickson's Broaden-and-Build theory (2001), yet in addition key emotions such as hope and love appeared to serve as a 'bridge' leading writers beyond the page and into constructive action, thus potentially breaking habits of unconstructive writing or rumination. Positive emotions seemed to function as a way for participants to reframe circumstances in a manner that subsequently related back to real-world experience; in other words they weren't just reflecting or lamenting, they were in a sense strategising future actions or developing the sense of selfefficacy necessary to overcome the challenge. Further, participants were better able to relate to others and behave in a more pro-social way.

Whilst it is not possible to generalise based on this small sample, one strong potential implication of the present study is that the writing journey for an individual, as Nicholls (2009) has previously alerted us to, may have many supplementary stages beyond simply divulging one's deepest thoughts and feelings. Fredrickson and colleagues $(1998 ; 2001)$ have argued that experiencing positive emotions can be a method of building resources, and they appear also to have this function in expressive writing. Further, the most novel aspect of the present study is that positive emotions appear to transform writing from a purely solitary practice into a tool for better relating to others and altering real experience, through providing a 'bridge' beyond the page - beyond simply ruminating on the challenge - and into action. Further, we posit that this positive reframing and bridging into actual action might initiate an 'upward spiral' for those utilising positive emotions in expressive writing (Fredrickson \& Joiner, 2002).

Niederhoffer and Pennebaker (2009, p.630) write that, "the path to a satisfying and fulfilling life does not bypass difficulties and negative thoughts and feelings... by openly facing our traumas we no longer end up in such psychological ditches. Rather we can begin to build bridges to the considerable strengths that we all possess." If facilitators and health professionals can find creative ways to assist clients in utilising positive emotions in expressive writing, we may begin to see the evolution of the practice into one that not only makes us feel better by facing our trauma, but also helps us flourish by assessing our strengths and resources.

Our suggestions for future research would be to develop further methods of encouraging participants to engage with positive emotions in expressive writing, without priming or restricting them. Further, we would invite other researchers to quantitatively assess this pilot intervention with a larger sample, as well as conduct a longitudinal study to assess any potential long-term effects of engaging with the PECs. In qualitative terms, it may also be of interest to seek further evidence for this novel 'bridge' effect of moving beyond the page and into constructive action, perhaps by closely analysing those emotions we found to be most strongly associated with this narrative, such as love. Finally, although not a focus of this study, a computerised language analysis of participant writings when using the PECs may serve to draw out more intricate linguistic changes, if any, and the implications of these.

\section{Authors}

Megan C. Hayes

Teesside University

megan@meganchayes.com

Kate Hefferon

University of East London 


\section{Publishing Timeline}

Received 6 May 2015

Accepted 28 September 2015

Published 18 December 2015

\section{References}

Aron, A., Aron, E. N., \& Smollan, D. (1992). Inclusion of Other in the Self Scale and the structure of interpersonal closeness. Journal of Personality and Social Psychology, 63(4), 596-612. http://dx.doi.org/10.1037/0022-3514.63.4.596

Ashby, F. G., \& Isen, A. M. (1999). A neuropsychological theory of positive affect and its influence on cognition. Psychological review, 106(3), 529-550. http://dx.doi.org/10.1037/0033-295X.106.3.529

Baikie, K. A., \& Wilhelm, K. (2005). Emotional and physical health benefits of expressive writing. Advances in Psychiatric Treatment, 11(5), 338-346. http://dx.doi.org/10.1192/apt.11.5.338

Baikie, K. A., Geerligs, L., \& Wilhelm, K. (2012). Expressive writing and positive writing for participants with mood disorders: An online randomized controlled trial. Journal of Affective Disorders, 136(3), 310319. http://dx.doi.org/10.1016/j.jad.2011.11.032

Braun, V., \& Clarke, V. (2006). Using thematic analysis in psychology. Qualitative Research in Psychology, 3(2), 77-101. http://dx.doi.org/10.1191/1478088706qp063oa

Burton, C. M., \& King, L. A. (2004). The health benefits of writing about intensely positive experiences. Journal of Research in Personality, 38(2), 150-163. http://dx.doi.org/10.1016/S0092-6566(03)00058-8

Burton, C. M., \& King, L. A. (2009). The health benefits of writing about positive experiences: The role of broadened cognition. Psychology and Health, 24(8), 867-879. http://dx.doi.org/10.1080/08870440801989946

Carr, A. (2011). Positive psychology: The science of happiness and human strengths. East Sussex: Routledge.

Condon, P., Wilson-Mendenhall, C. D., \& Feldman-Barrett, L. (2014). The psychological construction of positive emotion as a window into well-Being. In Gruber, J., \& Moskowitz, J. T. (Eds.). (2014). Positive emotion: Integrating the light sides and dark sides. New York: Oxford University Press. http://dx.doi.org/10.1093/acprof:oso/9780199926725.003.0002

Creswell, J. D., Lam, S., Stanton, A. L., Taylor, S. E., Bower, J. E., \& Sherman, D. K. (2007). Does selfaffirmation, cognitive processing, or discovery of meaning explain cancer-related health benefits of expressive writing? Personality and Social Psychology Bulletin, 33(2), 238-250. http://dx.doi.org/10.1177/0146167206294412

Danoff-Burg, S., Mosher, C. E., Seawell, A. H., \& Agee, J. D. (2010). Does narrative writing instruction enhance the benefits of expressive writing?. Anxiety, Stress, \& Coping, 23(3), 341-352. http://dx.doi.org/10.1080/10615800903191137

Frattaroli, J. (2006). Experimental disclosure and its moderators: a meta-analysis. Psychological Bulletin, 132(6), 823-865. http://dx.doi.org/10.1037/0033-2909.132.6.823

Fredrickson, B. L. (1998). What good are positive emotions? Review of General Psychology, 2(3), 300-319. http://dx.doi.org/10.1037/1089-2680.2.3.300

Fredrickson, B. L. (2001). The role of positive emotions in positive psychology: The Broaden-and-Build theory of positive emotions. American Psychologist, 56(3), 218-226. http://dx.doi.org/10.1037/0003066X.56.3.218

Fredrickson, B. L. (2009). Positivity. Three Rivers Press (CA).

Fredrickson, B. L. (2013). Love 2.0: How Our Supreme Emotion Affects Everything We Think, Do, Feel, and Become. New York: Hudson Street Press.

Fredrickson, B. L., \& Cohn, M. A. (2010). Positive Emotions. In M. Lewis, J. M. Haviland-Jones \& L. F. Barrett (Eds.), Handbook of Emotions (pp. 777-796). London: Guilford Press.

Fredrickson, B. L., \& Joiner, T. (2002). Positive emotions trigger upward spirals toward emotional wellbeing. Psychological science, 13(2), 172-175. http://dx.doi.org/10.1111/1467-9280.00431

Fredrickson, B. L., Cohn, M. A., Coffey, K. A., Pek, J., \& Finkel, S. M. (2008). Open hearts build lives: positive emotions, induced through loving-kindness meditation, build consequential personal 
resources. Journal of personality and social psychology, 95(5), 1045-1062. http://dx.doi.org/10.1037/a0013262

Gortner, E. M., Rude, S. S., \& Pennebaker, J. W. (2006). Benefits of expressive writing in lowering rumination and depressive symptoms. Behavior therapy, 37(3), 292-303. http://dx.doi.org/10.1016/j.beth.2006.01.004

Gruber, J., \& Moskowitz, J. T. (2014). Positive emotion: Integrating the light sides and dark sides. New York: Oxford University Press.

Guest, G., MacQueen, K. M., \& Namey, E. E. (2012). Applied Thematic Analysis. SAGE Publications, Inc.

Held, B. S. (2002). The tyranny of the positive attitude in America: Observation and speculation. Journal of Clinical Psychology, 58(9), 965-991. http://dx.doi.org/10.1002/jclp.10093

Hoyt, M. A., Austenfeld, J., \& Stanton, A. L. (2014). Processing coping methods in expressive essays about stressful experiences: Predictors of health benefit. Journal of Health Psychology, 1-11. [Epub ahead of print 29 September.] http://dx.doi.org/10.1177/1359105314550347

Isen, A. M. (1987). Positive affect, cognitive processes, and social behavior. Advances in Experimental Social Psychology, 20, 203-253. http://dx.doi.org/10.1016/S0065-2601(08)60415-3

Isen, A. M., Daubman, K. A., \& Nowicki, G. P. (1987). Positive affect facilitates creative problem solving. Journal of Personality and Social Psychology, 52(6), 1122-1131. http://dx.doi.org/10.1037/00223514.52.6.1122

Isen, A. M., \& Levin, P. F. (1972). Effect of feeling good on helping: Cookies and kindness. Journal of Personality and Social Psychology, 21(3), 384-388. http://dx.doi.org/10.1037/h0032317

Ivtzan, I., Lomas, T., Worth, P., \& Hefferon, K. (2015). Second-wave positive psychology: Embracing the dark side of life. London: Routledge.

Johnson, K. J., \& Fredrickson, B. L. (2005). "We all look the same to me" Positive emotions eliminate the own-race bias in face recognition. Psychological Science, 16(11), 875-881. http://dx.doi.org/10.1111/j.1467-9280.2005.01631.x

King, L. A. (2001). The health benefits of writing about life goals. Personality and Social Psychology Bulletin, 27(7), 798-807. http://dx.doi.org/10.1177/0146167201277003

King, L. A., \& Miner, K. N. (2000). Writing about the perceived benefits of traumatic events: Implications for physical health. Personality and Social Psychology Bulletin, 26, 220-230.

http://dx.doi.org/10.1177/0146167200264008

Lepore, S. J., \& Greenberg, M. A. (2002). Mending broken hearts: Effects of expressive writing on mood, cognitive processing, social adjustment and health following a relationship breakup. Psychology and Health, 17(5), 547-560. http://dx.doi.org/10.1080/08870440290025768

Lopez, S. J., \& Snyder, C. R. (2009). Oxford handbook of positive psychology (2nd ed.). New York: Oxford University Press. http://dx.doi.org/10.1093/oxfordhb/9780195187243.001.0001

Nicholls, S. (2009). Beyond expressive writing: Evolving models of developmental creative writing. Journal of Health Psychology, 14(2), 171-180. http://dx.doi.org/10.1177/1359105308100201

Niederhoffer, K. G., \& Pennebaker, J. W. (2009) Sharing one's story: On the benefits of writing or talking about emotional experience. In S. J. Lopez \& C. R. Snyder (Eds.), Oxford Handbook of Positive Psychology (pp. 621-632). New York: Oxford University Press. http://dx.doi.org/10.1093/oxfordhb/9780195187243.013.0059

Parks, A. C. \& Schueller, S. M. (2014). The Wiley-Blackwell Handbook of Positive Psychological Interventions. UK: John Wiley \& Sons. http://dx.doi.org/10.1002/9781118315927

Pennebaker, J. W. (1997). Writing about emotional experiences as a therapeutic process. Psychological science, 8(3), 162-166. http://dx.doi.org/10.1111/j.1467-9280.1997.tb00403.x

Pennebaker, J. W. (2004). Theories, therapies, and taxpayers: On the complexities of the expressive writing paradigm. Clinical Psychology: Science and Practice, 11(2), 138-142.

http://dx.doi.org/10.1093/clipsy.bph063

Pennebaker, J. W., \& Beall, S. (1986). Confronting a traumatic event: Toward an understanding of inhibition and disease. Journal of Abnormal Psychology, 95, 274-281. http://dx.doi.org/10.1037/0021$\underline{843 X .95 .3 .274}$ 
Pennebaker, J. W., \& Chung, C. K. (2007). Expressive writing, emotional upheavals, and health. In H. S. Freidman \& R. Cohen Silver (Eds.), Foundations of Health Psychology (pp. 263-284). New York: Oxford University Press.

Pennebaker, J. W., \& Chung, C. K. (2011). Expressive writing: Connections to physical and mental health. In H. S. Friedman (Ed.) Oxford Handbook of Health Psychology (pp. 417-437). New York: Oxford University Press. http://dx.doi.org/10.1093/oxfordhb/9780195342819.013.0018

Pennebaker, J. W., \& Seagal, J. D. (1999). Forming a story: The health benefits of narrative. Journal of Clinical Psychology, 55(10), 1243-1254. http://dx.doi.org/10.1002/(SICI)10974679(199910)55:10<1243::AID-JCLP6>3.0.CO;2-N

Poon, A., \& Danoff-Burg, S. (2011). Mindfulness as a moderator in expressive writing. Journal of Clinical Psychology, 67(9), 881-895. http://dx.doi.org/10.1002/jclp.20810

Seligman, M. E. P., \& Csikszentmihalyi, M. (2000) Positive psychology: An introduction. American Psychologist, 55(1), 5-14. http://dx.doi.org/10.1037//0003-066X.55.1.5

Seligman, M. E. P., Parks, N., \& Steen, T. A. (2004). A balanced psychology and a full life. The Royal Society, 359, 1379-1381. http://dx.doi.org/10.1098/rstb.2004.1513

Slatcher, R. B., \& Pennebaker, J. W. (2006). How Do I Love Thee? Let Me Count the Words: The Social Effects of Expressive Writing. Psychological Science, 17(8), 660-664. http://dx.doi.org/10.1111/j.14679280.2006.01762.x

Sloan, D. M., \& Marx, B. P. (2004). Taking pen to hand: Evaluating theories underlying the written disclosure paradigm. Clinical Psychology: Science and Practice, 11(2), 121-137. http://dx.doi.org/10.1093/clipsy.bph062

Snyder, C. R., Lopez, S. J., \& Pedrotti, J. T. (2010). Positive psychology: The scientific and practical explorations of human strengths. California: SAGE Publications.

Spera, S. P., Buhrfeind, E. D., \& Pennebaker, J. W. (1994). Expressive writing and coping with job loss. Academy of Management Journal, 37(3), 722-733. http://dx.doi.org/10.2307/256708

Stanton, A. L. (2011) Regulating emotions during stressful experiences: The adaptive utility of coping through emotional approach. In Folkman, S. (Ed.), The Oxford Handbook of Stress, Health, and Coping (pp.369-386). New York: Oxford University Press.

Tausczik, Y. R., \& Pennebaker, J. W. (2010). The psychological meaning of words: LIWC and computerized text analysis methods. Journal of Language and Social Psychology, 29(1), 24-54. http://dx.doi.org/10.1177/0261927X09351676

Teismann, T., Het, S., Grillenberger, M., Willutzki, U., \& Wolf, O. T. (2014). Writing about life goals: Effects on rumination, mood and the cortisol awakening response. Journal of Health Psychology, 19(11), 1410-1419. http://dx.doi.org/10.1177/1359105313490774

Wadlinger, H. A., \& Isaacowitz, D. M. (2006). Positive mood broadens visual attention to positive stimuli. Motivation and Emotion, 30(1), 87-99. http://dx.doi.org/10.1007/s11031-006-9021-1

Wing, J. F., Schutte, N. S., \& Byrne, B. (2006). The effect of positive writing on emotional intelligence and life satisfaction. Journal of Clinical Psychology, 62(10), 1291-1302. http://dx.doi.org/10.1002/jclp.20292

Wong, P. T. (2011). Positive psychology 2.0: Towards a balanced interactive model of the good life. Canadian Psychology/Psychologie Canadienne, 52(2), 69-81. http://dx.doi.org/10.1037/a0022511 